\title{
BMJ Open Association of workplace and population characteristics with prevalence of hypertension among Brazilian industry workers: a multilevel analysis
}

\author{
Daniele B Vinholes, ${ }^{1}$ Sérgio L Bassanesi, ${ }^{1}$ Hilton de Castro Chaves Junior, ${ }^{2}$ \\ Carlos Alberto Machado, ${ }^{3}$ Ione M F Melo, ${ }^{4}$ Flavio Danni Fuchs, ${ }^{5,6}$ \\ Sandra Costa Fuchs ${ }^{1,5}$
}

To cite: Vinholes DB, Bassanesi SL, Chaves Junior HdC, et al. Association of workplace and population characteristics with prevalence of hypertension among Brazilian industry workers: a multilevel analysis. BMJ Open 2017;7:e015755. doi:10.1136/ bmjopen-2016-015755

- Prepublication history for this paper is available online. To view these files please visit the journal online (http://dx.doi. org/10.1136/bmjopen-2016015755).

Received 29 December 2016 Revised 20 June 2017

Accepted 23 June 2017

CrossMark

For numbered affiliations see end of article.

Correspondence to Dr. Sandra Costa Fuchs; sfuchs@hcpa.edu.br

\section{ABSTRACT}

Background Exposure to risk factors for hypertension may be influenced by the characteristics of the workplace, where workers spend most of their daily time.

Objectives To evaluate the association between features of the companies, particularly the presence of facilities to provide meals, and of population characteristics and the prevalence of hypertension, taking into account individual risk factors for hypertension.

Material and methods This multilevel analysis was based on a cross-sectional study with individual and company data from the SESI (Serviço Social da IndústriaSocial Service of Industries) study and population-based data from the national census statistics. Workers aged $\geq 15$ years were randomly selected from small (20-99), medium (100-499) and large ( $\geq 500$ employees) companies per state using multistage sampling. Logistic regression was used to analyse the association between hypertension and individual, workplace and population variables, with odds ratios (0Rs; $95 \% \mathrm{Cl}$ ) adjusted for three-level variables. Results 4818 Workers from 157 companies were interviewed and their blood pressure, weight and height were measured. Overall, $77 \%$ were men, aged $35.4 \pm 10.7$ years, with $8.7 \pm 4.1$ years of schooling and mostly worked in companies with a staff canteen (66\%). Besides individual characteristics - being male, ageing, low schooling, alcohol abuse and higher $\mathrm{BMl}$ - a workplace with no staff canteen $(\mathrm{OR}=1.28 ; 95 \% \mathrm{Cl} 1.08$ to 1.52), small companies $(\mathrm{OR}=1.31$; $95 \% \mathrm{Cl} 1.07$ to 1.60 ) and living in cities with higher economic inequality ( $\mathrm{OR}=1.47 ; 95 \% \mathrm{Cl} 1.23$ to 1.76$)$ were associated with a higher risk for hypertension.

Conclusion Among Brazilian workers, the prevalence of hypertension is associated with individual risk factors, lack of a canteen at the workplace, small companies and higher economic inequalities of cities. These threelevel characteristics help to interpret differences in the prevalence of hypertension between regions or countries.

\section{BACKGROUND}

Hypertension has been a worldwide challenge for public health over the past
Strengths and limitation of this study

- Enrolment of a large random sample of industry workers from five regions of Brazil, including urban and rural areas.

- Inclusion of companies of different sizes and characteristics.

- Carrying out a multilevel analysis, including individual, workplace and population characteristics.

- The cross-sectional design of the study has no power to establish causality, particularly regarding the lack of temporality.

decades. ${ }^{1}$ Although it is possible to prevent, treat and control hypertension, rates of control remain unacceptably low. ${ }^{2}$ As a consequence, hypertension continues to have a leading role among risk factors for coronary heart disease, stroke, heart failure and chronic kidney disease. ${ }^{3}$ The consequences of hypertension and associated morbidities for the healthcare system increase the costs of providing long-term care and treatment, including hospitalisations and early retirement due to disability. Workplace costs increase owing to the loss or reduction of labour productivity and absenteeism of those who remain in the workforce. ${ }^{4}$

Some risk factors for hypertension are not modifiable, such as ancestry ${ }^{5}$ and ageing. ${ }^{6} 7$ Many other risk factors, however, can be targeted by interventions-for example stopping smoking, ${ }^{8}$ restricting sodium intake, ${ }^{9}$ increasing physical activity and intake of fruits, vegetables and whole

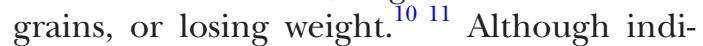
vidual characteristics are determinants of blood pressure levels, environmental exposures, such as those at the workplace, may 
mitigate or accentuate risk factors. ${ }^{12}$ In addition, the socioeconomic status of individuals, ${ }^{13} 14$ which can be measured by variation of income between cities and regions, may influence the prevalence of hypertension.

The effect of socioeconomic differences on the prevalence of hypertension can be analysed for an individual or on a larger scale for those in a workplace, ${ }^{15}$ population ${ }^{16}$ or even country. ${ }^{14}$ Multilevel models allow a network of individual features to be compiled at the same time as context variables of several levels, establishing a hierarchy among them. ${ }^{13}{ }^{14}$ The association between environmental characteristics and blood pressure ${ }^{1417}$ has been shown, but not simultaneously in the workplace and at the population level. ${ }^{17} 18$ This study presents the prevalence of hypertension among Brazilian workers and explores the influence of individual characteristics, features of the workplace and of the population where the workers live on the prevalence of hypertension.

\section{MATERIAL AND METHODS}

This multilevel analysis used data from a cross-sectional study: the SESI (Serviço Social da Indústria; Social Service of Industries) study, and the demographic census data available at the Brazilian Institute of Geography and Statistics (IBGE). Employees aged $\geq 15$ years who worked in industries or companies listed in the Annual Social Information List (RAIS) of the Ministry of Labour and Employment were eligible. The RAIS consists of a national registry of Brazilian public and private companies, with data on administration and employers registered with the National Institute of Social Security, regularly updated by regulatory agencies of each state. In each region, a state was randomly chosen to represent the region and, subsequently, cities, companies and workers were selected at random. Workers who were absent on the days of enrolment were not included. Workers selected from each company were invited to participate and those who agreed signed a consent form. The institutional review board and ethics committee of the Universidade Federal do Rio Grande do Sul, which is accredited by the Office of Human Research Protections as an institutional review board, approved the protocol.

\section{Sampling and sample size calculation}

Workers were randomly selected through multistage sampling. The first stage used simple random sampling to select one state for each region. Alagoas, Mato Grosso do Sul, Tocantins, Rio de Janeiro and Rio Grande do Sul were selected to represent the northeastern, centralwest, north, southeast and south regions, respectively. The second stage was conducted in a stratified random sample using the size of the companies listed in the RAIS, comprising small (20-99), medium (100-499) and large ( $\geq 500$ employees) companies in each state. The number of small, medium and large companies selected by state was established in proportion to the size of the stratum. The companies, sorted by city, were subsequently selected by systematic random sampling in each stratum. Before the data collection, the companies were visited by the supervisors to inform managers about the project, obtain the consent of the participating company and verify the structure of the company in order to generate a systematic random sample of workers. In each company, random systematic sampling was used to select workers. An epidemiologist and a statistician developed all sampling procedures and protocols for data collection. Two supervisors oversaw the fieldwork.

The sample size calculation was based on 5453439 workers registered in the RAIS, assuming a prevalence of hypertension ranging between $5 \%$ and $50 \%$, with a sampling error of $5 \%$. The prevalence ratio was calculated by the prevalence rate of hypertension among workers with a low level of schooling divided by the prevalence rate among workers with high level of schooling, for example. Using estimates ${ }^{16}$ of $12 \%$ prevalence of risk factors among those unexposed to low socioeconomic status and $18 \%$ among those exposed, with a ratio of $3: 1$, respectively, 2028 workers would be necessary to detect a prevalence ratio of at least 1.5 , with $90 \%$ power and $5 \%$ significance level (two-tailed). Since we had information about 4818 workers, we carried out the analysis on the full sample. The Statcalc module, of the EPINFO 2000 (Centres for Disease Control and Prevention, Atlanta, USA), version 3.3.2, was used in the sample size calculation.

\section{Study implementation}

Individual-level variables

Participants at the workplace were interviewed using a standardised questionnaire with 92 questions, which included assessment of demographic, socioeconomic, lifestyle, food intake and other characteristics. The questions have been previously tested. ${ }^{16}{ }^{19-21}$ In addition, a pilot study with 291 workers was carried out in one state, in order to verify whether the wording of the questionnaire was appropriate. The individual-level details included variables such as gender, age, years at school, current smoking, abusive alcohol consumption, physical activity and body mass index (BMI; weight $(\mathrm{kg}) /$ height $\left.\left(\mathrm{m}^{2}\right)\right)$ in the analysis. Age was categorised into 10-year-intervals. Formal education was categorised as $0-4,5-8$, 9-11, $\geq 12$ years completed at school. Physical activity was evaluated using the short form of the International Physical Activity Questionnaire (IPAQ), and categorised as high, moderate or low physical activity, according to the protocol. ${ }^{22}$ Alcohol consumption was investigated using a standardised questionnaire about type, frequency and amount of each beverage consumed in the 2 weeks before the interview. Abusive alcohol was determined as daily intake $\geq 30 \mathrm{~g}$ of ethanol, by men and $\geq 15 \mathrm{~g}$ by women. ${ }^{23}$ Interviews were carried out and patients were reassured about confidentiality.

With the subject in light clothing and barefoot, weight $(\mathrm{kg})$ was measured to the nearest $100 \mathrm{~g}$ with an electronic scale (Plenna, model Mea - 07400) and height $(\mathrm{cm})$ to 
the nearest $0.1 \mathrm{~cm}$ using a stadiometer (Tonelli, vertical model). Blood pressure measurements were carried out with an automatic oscillometric device (OMRON, model HEM-705 CP) using standardised techniques, which include previous resting for $5 \mathrm{~min}$ with the participant seated, feet straight on the ground and the arm over a surface with the antecubital fossa at the level of the heart. ${ }^{24}$ Hypertension was defined by the average of two blood pressure measurements $\geq 140 / 90 \mathrm{mmHg}$ or use of blood pressure lowering medication. ${ }^{25}$

\section{Company-level variables}

One hundred and fifty-seven companies in several cities of each state were selected and $93.1 \%$ agreed to participate. The presence of a canteen in the workplace and the size of the company were the variables of the company included in this analysis.

The availability of on-site canteens was investigated with administrative staff and confirmed with workers during data collection. The standardised questionnaire asked 'Does the company have a canteen?', 'Do you bring food from home?', 'Are meals served at work prepared by a food company?' and 'Does the company have a kitchen and cooks to prepare meals?". A staff canteen aims to provide healthy meals, reducing unhealthy dietary preferences. The potential effect of a staff canteen depends on the number of meals received by employees during working time-three meals in an 8-hour period. In this survey, dietary information was collected on food intake outside and at work. ${ }^{26}$

\section{Population-level variables}

The nationwide data collection for the census, performed by the IBGE, provided the number of inhabitants and the Gini coefficient. The number of inhabitants was categorised as $<100000$ or $\geq 100000$ inhabitants. The Gini coefficient is an international parameter used to measure inequality in income distribution among countries or regions. The coefficient varies between 0 and 1 ; values closer to 0 indicate low income inequality in a city and better income distribution. In this analysis, the distribution of the Gini coefficient for the whole sample was categorised as values $\leq 50$ th centile or values $>50$ th centile (high income inequality).

\section{Statistical analysis}

Data analysis was performed using the Statistical Package for Social Sciences (SPSS. Released 2009. PASW Statistics for Windows, Version 18.0. Chicago: SPSS Inc, Illinois, USA) and stratified by sex. All analyses were weighted by the sampling design. Logistic regression models were used to analyse the association between the prevalence of hypertension and company and population variables, adjusted for individual variables. This data analysis was conducted using MLwiN 2.19.

We fitted three models. Model I included individual-level variables: sex, age, years at school and body mass index. Model II incorporated model I individual-level variables and company-level variables: on-site staff canteen and company size. Finally, model III was built with the previous variables adjusted for a third level, population-level variables: number of inhabitants and the Gini coefficient. The model parameters were estimated by the penalised quasi-likelihood method, and odds ratios with 95\% CI were reported. The analysis was performed with fixed-effects variables entering sequentially, and missing values were excluded.

\section{RESULTS}

In total, 4818, out of 5000 workers, from 157 companies were interviewed. The participation rate of companies was $93.1 \%$ and that of workers, $96.4 \%$. Non-participation of workers was due to vacations or illnesses. The main reason for the non-participation of companies was the duration of the evaluations, which reduced employees' working hours on the days of data collection. In addition, a few companies listed in RAIS in the previous year had closed. The workers were aged, on average, 35.4 (SD 10.7) years, most were men $(76.5 \%)$, had completed 8.7 (SD 4.1) years at school, $65.7 \%$ worked in companies with an on-site staff canteen and $68.8 \%$ lived in cities with $\geq 100000$ inhabitants (table 1). At the individual level, prevalence of hypertension was higher among men, those aged $\geq 30$ years and who had a BMI between 18.5 and $29.9 \mathrm{~kg} / \mathrm{m}^{2}$. The non-adjusted analysis showed that at the company level, prevalence of hypertension was lower among those with a staff canteen, but it was not associated with the size of the company, and characteristics at the population level (table 1).

Figure 1 shows that prevalence of hypertension varied by the region of Brazil where the companies were situated and between men and women. The northeastern region had the highest prevalence $(35.1 \%)$ and the central west and south regions had the lowest rates $(19.0 \%$ and $19.8 \%$, respectively). Prevalence of hypertension was higher among men than women in all regions.

Table 2 presents the results of logistic regression models for variables in the first (individual), second (company) and third (population) level. At the first level, the independent risk of hypertension for male workers was approximately 2.7 times that for women, increased with age and BMI and was higher among those with $<9$ years of schooling and those who abused alcohol. At the second level, employees of non-canteen companies were at a higher risk of hypertension than those who worked in companies with a staff canteen, regardless of individual characteristics and company size. This company-level variable explained $4.5 \%$ of the prevalence of hypertension. For variables of the third level, living in highly populated cities and higher income inequities increased the risk of hypertension, independently of individual and workplace characteristics. The variance of the second level shifted to $1.0 \%$, and the third level explained $3.0 \%$ of the prevalence of hypertension. The full model at the third level shows 
Table 1 Risk factors for hypertension at the different levels of assessment

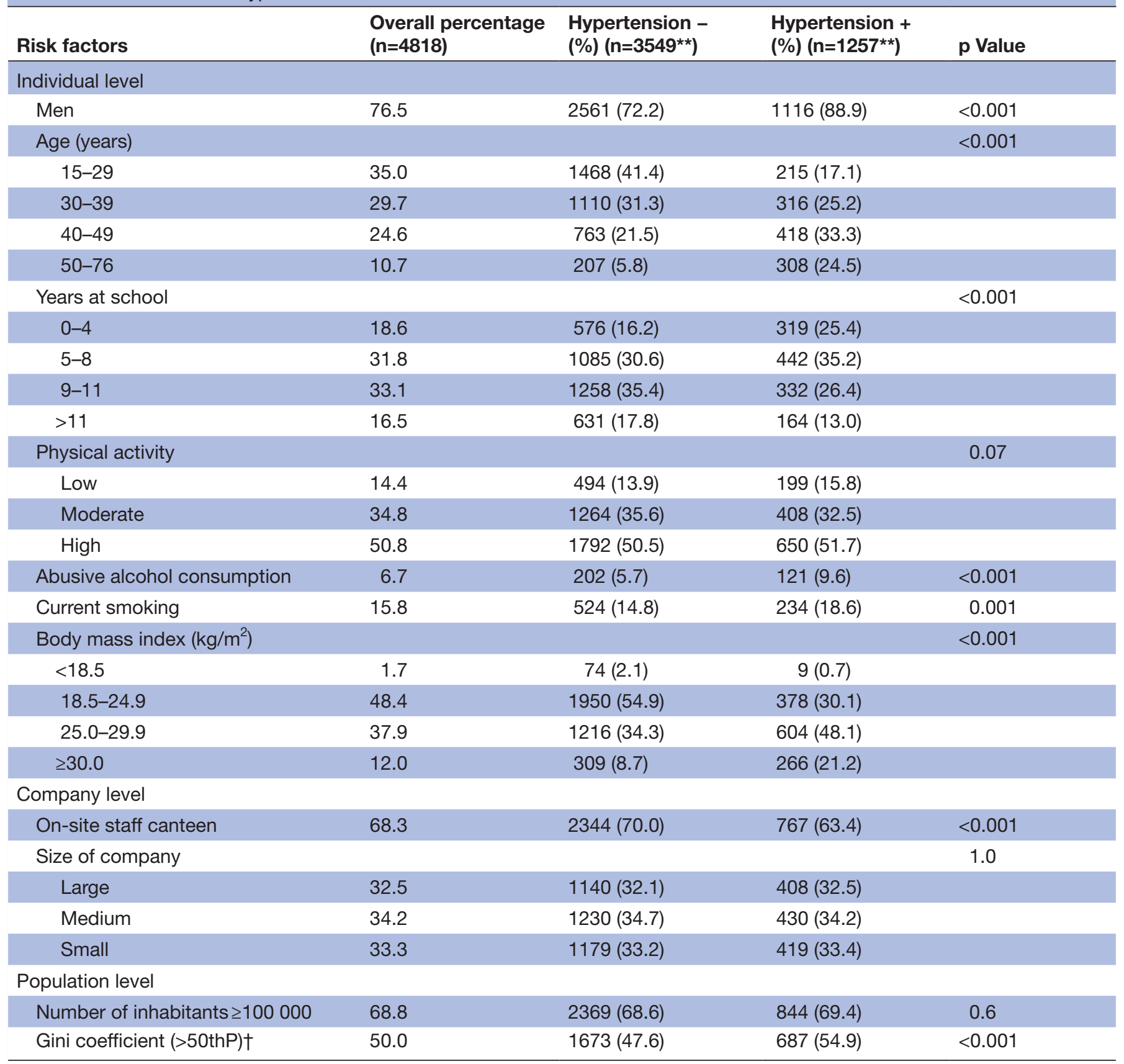

${ }^{*}$ Percentages were obtained in the analysis taking into account the sampling design

†The Gini coefficient is an international parameter used to measure the inequality in income distribution among countries. A Gini coefficient $>50$ th centile means high income inequality.

${ }^{* *}$ Numbers may not add to totals due to weight and rounding, beside missing information for hypertension ( $\left.n=17\right)$, Gini coefficient $(n=25)$, number of inhabitants $(n=125)$, and on-site staff canteen $(n=220)$.

that all individual characteristics, with the exception of smoking and physical activity, remained independently associated with hypertension. The size of company became statistically associated with the prevalence of hypertension after the multivariate analysis, with a risk for hypertension in workers of small size companies.

Differences in food intake according to the presence of an on-site staff canteen were observed in a secondary analysis. In companies with an on-site staff canteen, workers were more likely to consume more vegetables
(67.2\% vs $62.5 \%$; p=0.002), beans $(89.0 \%$ vs $86.5 \%$; $\mathrm{p}=0.002)$, leafy vegetables $(60.6 \%$ vs $53.2 \% ; \mathrm{p} \leq 0.001)$ than red meat $(41.8 \%$ vs $46.2 \% ; \mathrm{p}=0.02)$, salted meat $(2.3 \%$ vs $4.6 \% ; \mathrm{p} \leq 0.001)$ and sausage $(7.0 \%$ vs $8.8 \%$; $\mathrm{p}=0.04)$.

\section{DISCUSSION}

This multilevel analysis showed that population and workplace factors are associated with prevalence of 


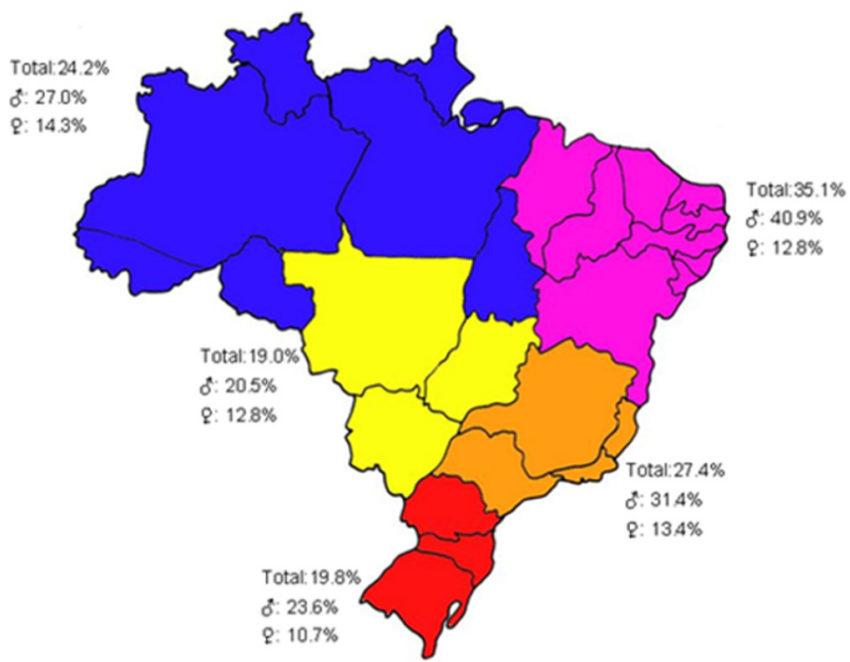

Figure 1 Prevalence of hypertension for men and women by regions of Brazil.

hypertension over and above individual-level characteristics, such as age, sex, years at school, smoking, physical activity and BMI. The presence of a canteen in the workplace may be associated with availability, variety and quality of healthy meals. The size of the company and, at the level of the population, the number of inhabitants of the city and the index of income inequalities, probably reflect other risks for hypertension not identified at the individual level.

Among workers, the analysis of individual-level risk factors confirmed higher prevalence ${ }^{27} 28$ and risk of hypertension among men, elderly workers, with less than middle school education ${ }^{29}$ and obese. ${ }^{30}$ Even though, this multilevel analysis showed a further influence of the macro-environment level on blood pressure. The presence of a staff canteen is part of Brazilian regulatory policy for companies with 300 or more employees and consequently, the workers do not take homemade meals to the workplace. In Brazil, canteens usually have nutritionists who supervise the preparation and provision of meals. The availability of canteens providing healthy meals in the workplace is not common in all countries. ${ }^{31}$ In addition, the presence of canteens also seems to reduce the consumption of snacks and drinks sold in vending machines. ${ }^{32} 33$ However, the availability of healthy food did not ensure its consumption. ${ }^{34}$

In this study, living in a city with greater number of inhabitants accounted for higher risk of hypertension, which persisted after controlling for individual, company characteristics and population economic inequalities. The number of inhabitants was used a proxy for the size of the city, which might account for the exposure to social, cultural, economic and regulatory policies. These features are likely to differ between large and small cities. Our results are in accordance with previous findings for population characteristics associated with individual systolic blood pressure. ${ }^{14}$ At the population level, physical activity, smoking, dietary practices and environmental pollution are some of the mechanisms linking urbanisation to the development of non-communicable diseases. ${ }^{35}$

Workplaces are the perfect setting for health promotion initiatives. ${ }^{36-38}$ Given that most of the adult population is employed and spends 8 or more hours a day in the workplace, it is a natural setting for promoting healthy habits aiming to reduce the prevalence of non-communicable disease. ${ }^{36}$ Thus, the workplace is a captive environment in which people can be contacted for recruitment and programme implementation. Strategies to prevent hypertension could include intervention at the company level, enabling staff canteens, even in small and medium-sized companies, health promotion programmes ${ }^{39}$ and dietary modification interventions. ${ }^{40}$ At the individual level, strategies could include interventions to control alcohol abuse and education about healthy eating. ${ }^{41}$ The implementation of joint interventions would probably be more effective, ${ }^{40}$ particularly if targeting a well-defined population. In addition, the increasing availability of fruits and vegetables in the workplace is possible when environmental changes and connections between employers and workers are developed. ${ }^{42}$

Our findings have some limitations. The cross-sectional design does not establish temporality and the possibility of reverse causality cannot be disregarded. Moreover, workplace-specific characteristics such as psychosocial work environment, physical factors and work task are potential sources of morbidity, which were not examined and should be investigated in further studies. The measurement of BP twice on 1 day to diagnose hypertension is a limitation, but it is unlikely that this potential error is unequally distributed among groups defined by different exposures. Moreover, definition of hypertension in observational studies is often based on two or three BP measurements, ${ }^{25}$ which differs from the recommendations for diagnosing hypertension. ${ }^{24}$

The strengths of our study includes a large random sample of workers, from five regions of Brazil, including urban and rural areas, and companies of small, medium and large size of a wide variety of industries, including, but not limited to, manufacturing, upstream and downstream industries and extractive industries, construction and service industries. This large representative sample of Brazilian workers was investigated to provide information on a poorly investigated spectrum of characteristics at the workplace level.

In conclusion, Brazilian workers have higher risks for hypertension when living in cities with a higher index of economic inequalities, working in small companies and without a canteen at the workplace. These risks were independent of ageing, sex, schooling, consumption of alcohol and body mass index. These findings help to explain the differences in hypertension by companies and regions of the country. 
Open Access

Table 2 Adjusted multilevel analysis of characteristics associated with hypertension (OR (95\% CI))

\begin{tabular}{|c|c|c|c|}
\hline Characteristics & Individual level* & $\begin{array}{l}\text { Individual + } \\
\text { company levelt }\end{array}$ & $\begin{array}{l}\text { Individual + company + } \\
\text { population level¥ }\end{array}$ \\
\hline \multicolumn{4}{|l|}{ Gender } \\
\hline Women & 1.00 & 1.00 & 1.00 \\
\hline Men & 2.68 (2.18 to 3.29$)$ & 2.71 (2.19 to 3.35$)$ & 2.78 (2.24 to 3.46$)$ \\
\hline$p$ Value & $<0.001$ & $<0.001$ & $<0.001$ \\
\hline \multicolumn{4}{|l|}{ Age (years) } \\
\hline $15-29$ & 1.00 & 1.00 & 1.00 \\
\hline $30-39$ & 1.61 (1.32 to 1.96$)$ & 1.75 (1.42 to 2.14$)$ & 1.71 (1.38 to 2.11$)$ \\
\hline $40-49$ & 2.80 (2.30 to 3.42 ) & 2.98 (2.43 to 3.66$)$ & 2.93 (2.38 to 3.62 ) \\
\hline $50-76$ & 7.20 (5.65 to 9.17$)$ & 8.31 (6.47 to 10.69$)$ & 8.24 (6.37 to 10.65$)$ \\
\hline p Value & $<0.001$ & $<0.001$ & $<0.001$ \\
\hline \multicolumn{4}{|l|}{ Years at school } \\
\hline $0-4$ & 1.51 (1.18 to 1.94$)$ & 1.51 (1.16 to 1.96$)$ & 1.48 (1.13 to 1.93$)$ \\
\hline $5-8$ & 1.58 (1.25 to 1.98$)$ & 1.45 (1.14 to 1.84$)$ & 1.43 (1.12 to 1.82$)$ \\
\hline $9-11$ & 1.16 (0.92 to 1.46$)$ & 1.17 (0.92 to 1.48$)$ & 1.12 (0.88 to 1.43$)$ \\
\hline$>11$ & 1.00 & 1.00 & 1.00 \\
\hline$p$ Value & $<0.001$ & 0.003 & 0.004 \\
\hline \multicolumn{4}{|l|}{ Physical activity } \\
\hline Low & 1.11 (0.90 to 1.38$)$ & 1.09 (0.88 to 1.36$)$ & 1.07 (0.85 to 1.34$)$ \\
\hline Moderate & 0.96 (0.82 to 1.13$)$ & 0.94 (0.80 to 1.11$)$ & 0.95 (0.810 to 1.13$)$ \\
\hline High & 1.00 & 1.00 & 1.00 \\
\hline$p$ Value & 0.5 & 0.4 & 0.6 \\
\hline \multicolumn{4}{|c|}{ Abusive alcohol consumption } \\
\hline No & 1.00 & 1.00 & 1.00 \\
\hline Yes & 1.58 (1.22 to 2.06$)$ & 1.54 (1.17 to 2.02$)$ & 1.62 (1.22 to 2.16$)$ \\
\hline p Value & 0.001 & 0.002 & 0.001 \\
\hline \multicolumn{4}{|l|}{ Current smoking } \\
\hline No & 1.00 & 1.00 & 1.00 \\
\hline Yes & 1.13 (0.94 to 1.37$)$ & $1.08(0.89$ to 1.32$)$ & 1.06 (0.87 to 1.29$)$ \\
\hline $\mathrm{p}$ Value & 0.19 & 0.4 & 0.6 \\
\hline \multicolumn{4}{|c|}{ Body mass index $\left(\mathrm{kg} / \mathrm{m}^{2}\right)$} \\
\hline$<18.5$ & 1.00 & 1.00 & 1.00 \\
\hline $18.5-24.9$ & 1.49 (0.67 to 2.32$)$ & $1.46(0.68$ to 3.13$)$ & 1.48 (0.69 to 3.19$)$ \\
\hline $25.0-29.9$ & 3.19 (2.37 to 4.02$)$ & $3.13(1.46$ to 6.69$)$ & 3.26 (1.52 to 7.02$)$ \\
\hline$\geq 30.0$ & 6.01 (5.18 to 6.85$)$ & 5.83 (2.69 to 12.65$)$ & 5.76 (2.63 to 12.59$)$ \\
\hline p Value & $<0.001$ & $<0.001$ & $<0.001$ \\
\hline \multicolumn{4}{|c|}{ On-site staff canteen } \\
\hline Yes & - & 1.00 & 1.00 \\
\hline No & - & 1.31 (1.11 to 1.54$)$ & 1.28 (1.08 to 1.52$)$ \\
\hline p Value & & 0.001 & 0.004 \\
\hline \multicolumn{4}{|l|}{ Size of company } \\
\hline Small & - & 1.19 (0.99 to 1.44$)$ & 1.31 (1.07 to 1.60$)$ \\
\hline Medium & - & 1.12 (0.94 to 1.34$)$ & 1.06 (0.88 to 1.28$)$ \\
\hline Large & - & 1.00 & 1.00 \\
\hline$p$ Value & & 0.17 & 0.02 \\
\hline
\end{tabular}


Table 2 Continued

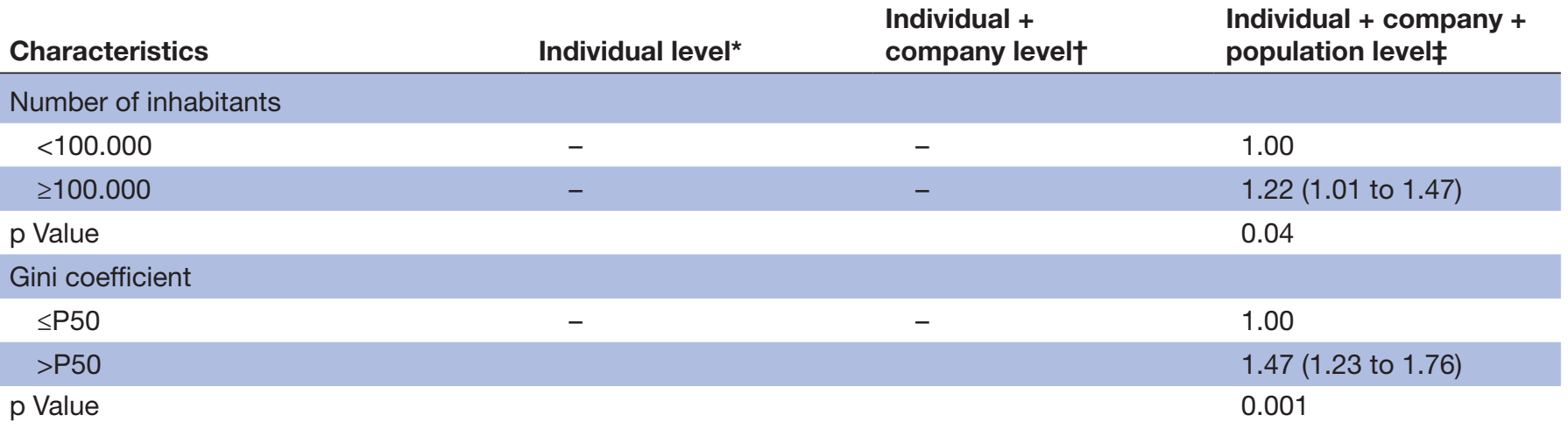

${ }^{*}$ OR adjusted for gender, age, years at school and body mass index (BMI).

†OR adjusted for gender, age, years at school, BMI, size of company and on-site canteen.

‡OR adjusted for gender, age, years at school, BMI, on-site canteen, size of company, number of inhabitants Gini coefficient above 50th centile.

\section{Author affiliations}

${ }^{1}$ Postgraduate Studies Program in Epidemiology, School of Medicine, Universidade Federal do Rio Grande do Sul, Porto Alegre, Rio Grande do Sul, Brazil

${ }^{2}$ Departament of Clinical Medicine, Universidade Federal de Pernambuco, Recife, Pernambuco, Brazil

${ }^{3}$ Department of Cardiology, School of Medicine, Universidade Federal de São Paulo (UNIFESP), São Paulo, Brazil

${ }^{4}$ Formerly at Unit of Health and Safety of Work, Serviço Social da Indústria (SESI), Brasilia, Brazil

${ }^{5}$ Postgraduate Studies Program in Cardiology, School of Medicine, Universidade Federal do Rio Grande do Sul, Porto Alegre, Rio Grande do Sul, Brazil ${ }^{6}$ Division of Cardiology, Hospital de Clínicas de Porto Alegre, Porto Alegre, Rio Grande do Sul, Brazil

Contributors HdCC, CAM, IMFM, FDF, SCF made substantial contributions to conception and design; DBV, FDF, SLB, SCF analysed and interpreted the data; DBV, CAM, HdCC, IMFM helped to draft the manuscript, and DBV, FDF, SLB, SCF reviewed the manuscript critically for important intellectual content. The authors had full access to all of the data in the study and DBV and SCF take responsibility for the contents of the article. All authors gave final approval of the version to be published.

Funding The SESI Study was supported and funded by the Pan American Health Organization (PAHO) and the Brazilian Ministry of Health. DBV received a fellowship from Coordination for the Improvement of Higher Education Personnel (CAPES) and SCF received a fellowship from National Counsel of Technological and Scientific Development (CNPq). PAHO, Brazilian Ministry of Health, CAPES, and CNPq played no part in the study design, data analysis, results interpretation or drafting of the manuscript.

Competing interests None declared.

Patient consent Obtained.

Ethics approval Research ethics committee of the Universidade Federal do Rio Grande do Sul.

Provenance and peer review Not commissioned; externally peer reviewed.

Data sharing statement The additional data report from the study is available to researchers at: http://vidasaudavelempresa.sesi.org.br/portal/lumis/portal/file/file Download.jsp?fileld=FF8080812B3B9D27012B3F0989CA1B9C

Open Access This is an Open Access article distributed in accordance with the Creative Commons Attribution Non Commercial (CC BY-NC 4.0) license, which permits others to distribute, remix, adapt, build upon this work non-commercially, and license their derivative works on different terms, provided the original work is properly cited and the use is non-commercial. See: http://creativecommons.org/ licenses/by-nc/4.0/

(c) Article author(s) (or their employer(s) unless otherwise stated in the text of the article) 2017. All rights reserved. No commercial use is permitted unless otherwise expressly granted.

\section{REFERENCES}

1. NCD Risk Factor Collaboration (NCD-RisC). Worldwide trends in blood pressure from 1975 to 2015: a pooled analysis of 1479 population-based measurement studies with 19.1 million participants. Lancet 2017;389:37-55.

2. Mozaffarian D, Benjamin EJ, Go AS, et al. Heart Disease and Stroke Statistics-2016 Update: A Report From the American Heart Association. Circulation 2016;133:38-60.

3. Rapsomaniki E, Timmis A, George J, et al. Blood pressure and incidence of twelve cardiovascular diseases: lifetime risks, healthy life-years lost, and age-specific associations in 1.25 million people. Lancet 2014;383:1899-911.

4. Bauer UE, Briss PA, Goodman RA, et al. Prevention of chronic disease in the 21st century: elimination of the leading preventable causes of premature death and disability in the USA. Lancet 2014;384:45-52.

5. Ferdinand KC. Management of high blood pressure in African Americans and the 2010 ISHIB consensus statement: meeting an unmet need. J Clin Hypertens 2010;12:237-9.

6. Keyhani S, Scobie JV, Hebert PL, et al. Gender disparities in blood pressure control and cardiovascular care in a national sample of ambulatory care visits. Hypertension 2008;51:1149-55.

7. Qato DM, Lindau ST, Conti RM, et al. Racial and ethnic disparities in cardiovascular medication use among older adults in the United States. Pharmacoepidemiol Drug Saf 2010;19:834-42.

8. Bowman TS, Gaziano JM, Buring JE, et al. A prospective study of cigarette smoking and risk of incident hypertension in women. J Am Coll Cardiol 2007;50:2085-92.

9. He FJ, Pombo-Rodrigues S, Macgregor GA. Salt reduction in England from 2003 to 2011: its relationship to blood pressure, stroke and ischaemic heart disease mortality. BMJ Open 2014;4:e004549.

10. Earnest CP, Church TS. Evaluation of a voluntary work site weight loss program on hypertension. J Occup Environ Med 2016;58:1207-11.

11. Forman JP, Stampfer MJ, Curhan GC. Diet and lifestyle risk factors associated with incident hypertension in women. JAMA 2009;302:401-11.

12. Babu GR, Jotheeswaran AT, Mahapatra T, et al. Is hypertension associated with job strain? A meta-analysis of observational studies. Occup Environ Med 2014;71:220-7.

13. Dragano N, Bobak M, Wege N, et al. Neighbourhood socioeconomic status and cardiovascular risk factors: a multilevel analysis of nine cities in the Czech Republic and Germany. BMC Public Health 2007;7:255

14. Merlo J, Asplund K, Lynch J, et al. Population effects on individual systolic blood pressure: a multilevel analysis of the World Health Organization MONICA Project. Am J Epidemiol 2004;159:1168-79.

15. Capingana DP, Magalhães $P$, Silva $A B$, et al. Prevalence of cardiovascular risk factors and socioeconomic level among publicsector workers in Angola. BMC Public Health 2013;13:732.

16. Fuchs SC, Moreira LB, Camey SA, et al. Clustering of risk factors for cardiovascular disease among women in Southern Brazil: a population-based study. Cad Saude Publica 2008;24 Suppl 2:s285-s293. 
17. Chaix $B$, Ducimetière $P$, Lang $T$, et al. Residential environment and blood pressure in the PRIME study: is the association mediated by body mass index and waist circumference? J Hypertens 2008;26:1078-84.

18. Matheson Fl, White HL, Moineddin R, et al. Neighbourhood chronic stress and gender inequalities in hypertension among Canadian adults: a multilevel analysis. J Epidemiol Community Health 2010;64:705-13.

19. Henn RL, Fuchs SC, Moreira LB, et al. Development and validation of a food frequency questionnaire (FFQ-Porto alegre) for adolescent, adult and elderly populations from Southern Brazil. Cad Saude Publica 2010;26:2068-79.

20. Trevisol DJ, Moreira LB, Fuchs FD, et al. Health-related quality of life and awareness of hypertension. J Hypertens 2012;30:629.

21. Riegel G, Moreira LB, Fuchs SC, et al. Long-term effectiveness of non-drug recommendations to treat hypertension in a clinical setting. Am J Hypertens 2012;25:1202-8.

22. Craig CL, Marshall AL, Sjöström M, et al. International physical activity questionnaire: 12 -country reliability and validity. Med Sci Sports Exerc 2003;35:1381-95.

23. Moreira LB, Fuchs FD, Moraes RS, et al. Alcoholic beverage consumption and associated factors in Porto Alegre, a southern Brazilian city: a population-based survey. J Stud Alcohol 1996;57:253-9.

24. Malachias MVB, Gomes MAM, Nobre F, et al. $7^{\text {th }}$ Brazilian guideline of arterial hypertension: chapter 2 - Diagnosis and classification. Arq Bras Cardiol 2016;107:7-13.

25. WHO MONICA Project. MONICA manual, part III: population survey, section 1:population survey data component. Volume 2012, 1997. http://www.thl.fi/publications/monica/manual/part3/iii-1.htm.

26. Vinholes DB, Melo IM, Machado CA, et al. The association between socioeconomic characteristics and consumption of food items among Brazilian industry workers. ScientificWorldJournal 2012;2012:1-14.

27. Cassani RS, Nobre F, Pazin Filho A, et al. Prevalence of cardiovascular risk factors in a population of Brazilian industry workers. Arq Bras Cardiol 2009;92:16-22.

28. Matos MF, Souza e Silva NA, Pimenta AJ, et al. Prevalence of risk factors for cardiovascular disease in employees of the Research Center at Petrobras. Arq Bras Cardiol 2004;82:5-8.
29. Ganesh Kumar S, Deivanai Sundaram N. Prevalence and risk factors of hypertension among bank employees in Urban Puducherry, India. Int J Occup Environ Med 2014;5:94-100.

30. Bosu WK. The prevalence, awareness, and control of hypertension among workers in West Africa: a systematic review. Glob Health Action 2015;8:26227.

31. Tin SP, Lam WW, Yoon S, et al. Workplace health promotion: assessing the cardiopulmonary risks of the construction workforce in Hong Kong. PLoS One 2016;11:e0146286.

32. Roos E, Sarlio-Lähteenkorva S, Lallukka T. Having lunch at a staff canteen is associated with recommended food habits. Public Health Nutr 2004;7:53-61.

33. Raulio S, Roos E, Prättälä R. School and workplace meals promote healthy food habits. Public Health Nutr 2010;13:987-92.

34. Bingham CM, Lahti-Koski M, Puukka P, et al. Effects of a healthy food supply intervention in a military setting: positive changes in cereal, fat and sugar containing foods. Int J Behav Nutr Phys Act 2012;9:91.

35. Allender S, Wickramasinghe K, Goldacre M, et al. Quantifying urbanization as a risk factor for noncommunicable disease. J Urban Health 2011;88:906-18.

36. Chu C, Driscoll T, Dwyer S. The health-promoting workplace: an integrative perspective. Aust N Z J Public Health 1997;21:377-85.

37. Rongen A, Robroek SJ, van Lenthe FJ, et al. Workplace health promotion: a meta-analysis of effectiveness. Am J Prev Med 2013;44:406-15.

38. Lassen AD, Ernst L, Poulsen S, et al. Effectiveness of a canteen take away concept in promoting healthy eating patterns among employees. Public Health Nutr 2012;15:452-8.

39. Eng JY, Moy FM, Bulgiba A. Impact of a workplace health promotion program on employees' blood pressure in a public university. PLoS One 2016;11:e0148307.

40. Geaney F, Kelly C, Greiner BA, et al. The effectiveness of workplace dietary modification interventions: a systematic review. Prev Med 2013;57:438-47.

41. Groeneveld IF, Proper KI, van der Beek AJ, et al. Short and long term effects of a lifestyle intervention for construction workers at risk for cardiovascular disease: a randomized controlled trial. BMC Public Health 2011;11:836.

42. Thorsen AV, Lassen AD, Tetens I, et al. Long-term sustainability of a worksite canteen intervention of serving more fruit and vegetables. Public Health Nutr 2010;13:1647-52. 